https://doi.org/10.22225/wicaksana.5.2.2021.81-86

\title{
FAKTOR-FAKTOR YANG MEMPENGARUHI KINERJA AUDITOR INTERNAL PEMERINTAH DAERAH PADA BPKP RI PERWAKILAN PROVINSI BALI
}

\author{
Erminilda Alvionita Lehot ${ }^{1}$, Luh Kadek Datrini ${ }^{2}$, I.B. Made Putra Manuaba ${ }^{3}$ \\ Fakultas Ekonomi dan Bisnis Universitas Warmadewa
}

\begin{abstract}
ABSTRAK
Pada riset yang sedang saya buat ini menjelasakan tentang judul yang dibuat ini. Yang dimana meneruskan suatu masalah untuk bisa dikaji lebih dalam pada riset yang saya buat ini dimana apakah pemahaman good governance, ketidakjelasan peran, komitmen organisasi, kerahasiaan dan locus of control berpengaruh pada kinerja auditor. Serta pada saat melakukan sebuah riset sudah mencari data untuk bisa diteliti dan untuk dikumpulkan melalui penyebaran kuesioner. Dengan menggunakan jenis data yang bisa digunakan pada saat meneliti dengan menggunakan data kuantitatif. Dan pada saat melakukan riset mendapatkan jumlah sampel sebanyak 88 responden yang bisa ditentukan dengan menggunakan jawaban sampel jenuh. Dimana pada saat melakukan penelitian sudah bisa menggunakan teknik analisis data serta data yang digunakan pada riset tersebut yaitu uji instrumen, lalu asumsi klasik, dan terakhir uji hipotesis. Dan dari semua hasil telah mendapatkan jawaban dan kesimpulan bahwa good governance berpengaruh terhadap kinerja auditor. Pada jawaban ketidakjelasan peran tidak berpengaruh terhadap kinerja auditor. Sedangkan jawaban dari komitmen organisasi juga tidak berpengaruh terhadap kinerja. Dan pada kerahasiaan mendapatkan jawaban adanya pengaruh positif terhadap kinerja. Sedangkan pada locus of control mendapatkan jawaban adanya pengaruh positif terhadap kinerja.
\end{abstract}

Kata kunci: Auditor, Kinerja Auditor, BPKP RI, Good Governance

\section{PENDAHULUAN}

Dalam melakukan sebuah prosesi pada saat melakukan kegiatan dimana memiliki sebuah peranan sosial yang sangat berkaitan dengan tugas dan tanggungjawab, dalam menjalankan profesi ini dimana audior harus bisa menjalankan tugas yang lebih serius dalam melaksanakan sebuah aturan pada profesi dalam melaksanakan tugas serta tanggungjawab. Untuk bisa menciptakan perilaku yang profesional maka auditor harus bisa memiliki sebuah karakteristik yang sangat cukup berat dimana agar bisa mendapatkan kualitas jasa yang sudah dihasilkan. Kualitas yang dihasilkan dapat melalui pemahaman dan komitmen dalam menjalankan sebuah standar yang sudah ditentukan ini.

Dengan adanya sebuah tuntutan dari masyarakat untuk bisa menciptakan tatanan yang baik maka dari itu penyelenggara 
organisasi pada sektor ini harus bisa secara efektif, efesien dan transparan serta bersih dan bebas dari semua kegiatan yang menyalahgunakan wewenang untuk bisa meningkatkan pengembangan dan pengawasan secara internal. Dengan tatanan kelola yang baik dan bersih maka semua kegiatan pada suatu kalangan memiliki kualitas yang tinggi, jujur serta bertanggungjawab terhadap masyarakat. Serta pada sektor ini dituntut untuk bisa melakukan tatanan kelola yang sangat baik agar tata kelola yang baik disetiap sektor ini.

Dimana pada sektor diberikan suatu kewenangan khusus untuk bisa mengatur dan mengurus untuk kepentingan masyarakat setempat untuk menurut prakarsa, serta tidak terkecuali dala bidang keuangan daerah. Untuk bisa mendapatkan kegiatan pelaksanaan maka dituntut untuk bisa memberikan pertanggungjawaban atas pelaksanaan yang wajib menyampaikan pertanggungjawaban atas pelaksanaan. Pada dasarnya penyelenggara harus turut wajib menyapaikan pertanggungjawaban kepada masyarakat. Dengan adanya pola pertanggungjawaban ini sesuai dengan ajaran yang sudah didapat makan sektor ini merupakan suatu kegiatan dari rakyat dan dalam hal ini rakyat dapat diwakili.

Dalam melaksanan fungsinya pengawas berupa suatu kegiatan yang diperlukan adanya dukungan dari semua kinerja, maka akan didapat efektif dan optimal dalam menjalankan semua kegiatan. Dan para kinerja merupakan suatu kemampuan yang dihasilkan atas pengelola dan tanggung jawab yang sudah dilakukan dalam satu tim. Dengan didapatnya prinsip-prinsip seperti integritas, obyektivitas serta kerahasiaan maka diperlunya bertindak jujur dalam melaksanakan kegiatan. Disamping itu juga terhadap organisasi juga diperlukan untuk bisa mengukur terhadap loyalitas organisasi dimana dia bekerja.

\section{TINJAUAN PUSTAKA}

\section{Kinerja Individu}

Dimana dalam menjalankan entitas ini maka dituntut harus memiliki pegawai atau karyawan yang berkualitas karna untuk bisa mendapatkan pegawai yang berkualitas yang baik maka harus memiliki penerapan pada kinerja. Sedangkan dalam suatu hal yang berbeda beda ini maka adanya faktor pendorong yang berbeda beda.

\section{Auditor}

1. Auditor pemerintah

Merupakan pekerjaan yang berbagai tingkatan bekerja pada sektor yang bertugas pada pokok yaitu melakukan pertanggungjawaban yang sudah disajikan oleh unit.

2. Auditor internal

Adalah suatu kegiatan pekerjaan pada suatu sektor dan oleh karnanya status yang diberikan yaitu pegawai tugas yang diterima terutama untuk ditujukan untuk bisa membantu manajemen ditempat dia bekerja.

3. Auditor independen

Merupakan suatu tindakan yang sebagai praktisi perorangan yang memberikan jasa profesional kepada klien. Yang 
umumnya diberikan kepada mereka yang lulus dalan ujian.

\section{Kinerja Auditor}

Merupakan suatu hasil yang sedang dikerjakan yang menggambarkan kualitas dan kuantits atas yang dikerjakan dan telah dicapai oleh seseorang dalam melaksanakan tugasnya.

\section{Good Governance}

Adalah suatu tatanan kelola yang dilakukan baik pada unit usaha dalam berkarya yang dimana penyelenggara manajemen membangun suatu keadaan yang bertanggungjawab dan sejalan dalam menerapkan prinsin.

\section{Ketidakjelasan Peran}

Yaitu suatu ketidak cukupan informasi yang dimiliki serta tidak ada layanan yang jelas terhadap perilakuk yang sudah dilakukan. Dimana dalam mengalami ketidakjelasan mereka merasa tidak ada kejelasan yang sehubungan dengan ekspetasi dalam pekerjaan.

\section{Komitmen Organisasi}

Suatu adanya perpaduan antara sikap dan perilaku yang menyangkut sikap rasa identifikasi, rasa yang terlibat serta rasa kesetiaan. Dimana dalam melakukannya karyawan harus setia terhadap organisasi.

\section{Kerahasiaan}

Adalah suatu sikap yang diharuskan untuk bisa menghargai nilai kepemilikan informasi yang sudah diberikan dan diterima. Dalam melakukan pemeriksaan hanya dapat untuk mengungkapkan informasi yang sudah diperoleh.

\section{Locus of Control}

Yaitu sebuah konsep yang digunakan secara luas dalam melakukan riset keprilakuan serta menjelaskan perbedaan antar individu.

\section{Publikasi Penelitian Sebelumnya}

Dalam melakukan riset sudah didapat hasil pada kinerja berupa yang pertama engelita. kneefel, julie. sondakh, lidia mawikere (2018), kedua rizki uatri dauly (2020), ketiga juwita taringan, anggie charolina, citra evangelita, ega marito (2019).

\section{Hipotesis}

$\mathrm{H}_{1}$ : pemahaman good governance mendapatkan jawaban positif

$\mathrm{H}_{2}$ : ketidakjelasan juga mendapatkan jawaban yang positif

$\mathrm{H}_{3}$ : komitmen organisasi mendapatkan hasil yang positif

$\mathrm{H}_{4} \quad$ : kerahasiaan menjelaskan jawaban yang positif

$\mathrm{H}_{5} \quad$ : locus of control mendapatkan hasil jawaban yang positif

\section{METODOLOGI PENELITIAN}

Pada saat sedang melakukan riset yang dimana bertempat pada BPKP RI Perwakilan Bali dengan ruang lingkup pada seluruh anggota. Sedangkan dalam melakukan riset penelitian mendapatkan kualitas dan kuantitas dalam menjalankan pemeriksaan pada tempat ini. Sedangkan dalam melakukan riset sudah mendapatkan hasil jawaban populasi dimana mendapatkan jawaban sebanyak 88 orang. 


\section{Teknik Analisis Data}

Dari uji yang sudah dilakukan pada riset ini maka menggunakan jawaban liniear berganda.

\section{Hasil dan Pembahasan}

\section{Validitas}

Dimana saat melakukan riset pada jawaban tersebut menjelaskan bahwa semua jawaban kuesioner dinyatakan valid pada saat pengumpulan.
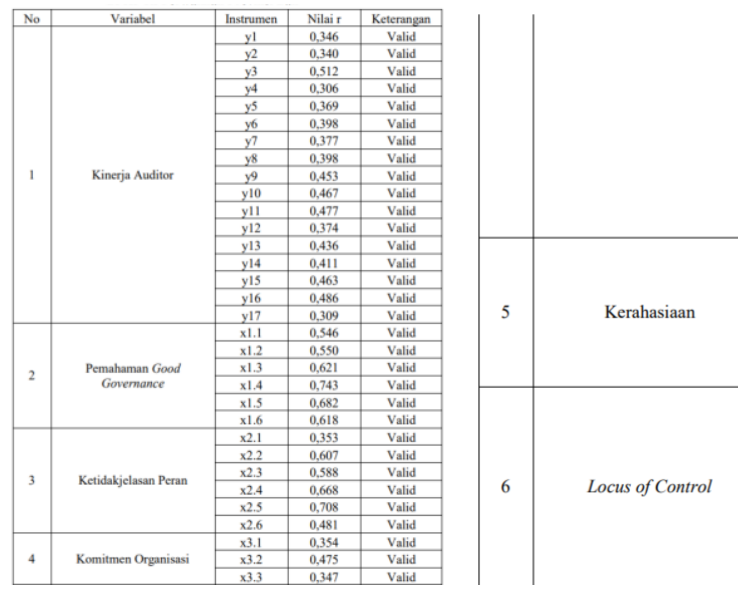

\begin{tabular}{|c|c|c|}
\hline x3.4 & 0,450 & Valic \\
\hline$\times 3.5$ & 0,537 & Valic \\
\hline$\times 3.6$ & 0,314 & Valic \\
\hline $\mathrm{x} 3.7$ & 0,649 & Valic \\
\hline $\mathrm{x} 3.8$ & 0,59 & Valic \\
\hline$\times 3.9$ & 0,427 & Valic \\
\hline$\times 3.10$ & 0,501 & Valic \\
\hline $\mathrm{x} 3.11$ & 0,440 & Valic \\
\hline$\times 3.12$ & 0,415 & Valic \\
\hline$\times 4.1$ & 0,465 & Valic \\
\hline$x 4.2$ & 0,615 & Valic \\
\hline$\times 4.3$ & 0,615 & Valic \\
\hline$x 4.4$ & 0,595 & Valic \\
\hline$\times 4.5$ & 0,550 & Valic \\
\hline$\times 4.6$ & 0,665 & Valic \\
\hline$\times 5.1$ & 0,509 & Valic \\
\hline$\times 5.2$ & 0,572 & Valic \\
\hline$\times 5.3$ & 0,339 & Valic \\
\hline$\times 5.4$ & 0,520 & Valic \\
\hline$\times 5.5$ & 0,467 & Valic \\
\hline$\times 5.6$ & 0,537 & Valic \\
\hline$\times 5.7$ & 0,523 & Valic \\
\hline$\times 5.8$ & 0,566 & Valic \\
\hline
\end{tabular}

\section{Uji Reabilitas}

Dimana dari hasil jawaban diatas menjelaskan bahwa semua variabel peneltian telah memenuhi syarat pada uji yang sudah dilakukan sehingga dapat digunakan sebagai instrument pengumpulan data.

\begin{tabular}{|c|l|c|c|} 
No & \multicolumn{1}{|c|}{ Variabel } & $\begin{array}{c}\text { Nilai Cronbach's } \\
\text { Alpa }\end{array}$ & Keterangan \\
\hline 1 & Kinerja Auditor & 0,703 & Reliabel \\
\hline 2 & $\begin{array}{l}\text { Pemahaman Good } \\
\text { Governance }\end{array}$ & 0,749 & Reliabel \\
\hline 3 & Ketidakjelasan Peran & 0,726 & Reliabel \\
\hline 4 & Komitmen Organisasi & 0,701 & Reliabel \\
\hline 5 & Kerahasiaan & 0,732 & Reliabel \\
\hline 6 & Locus of Control & 0,706 & Reliabel \\
\hline
\end{tabular}

\section{Normalitas}

Dari jawaban yang sudah diteliti terlebih dahulu maka menjelaskan bahwa semua data yang digunakan sudah berdistribusi normal.

\begin{tabular}{|ll|r|}
\hline & & \multicolumn{1}{|c|}{$\begin{array}{c}\text { Unstandardized } \\
\text { Residual }\end{array}$} \\
\hline $\mathrm{N}$ & Mean & 70 \\
Normal Parameters & Std. & 0,000000 \\
& Deviation & 2,50260261 \\
& Absolute & 0,086 \\
Most Extreme Differences & Positive & 0,086 \\
& Negative & $-0,076$ \\
& & 0,086 \\
Test Statistic & & 0,200 \\
Asymp. Sig. (2-tailed) & & \\
\hline
\end{tabular}

\section{Uji Multikolonieritas}

Dalam menjalankan riset ini menujukkan hasil jawaban yang digunakan dalam riset ini merupakan data yang tidak mengalami gejala.

\begin{tabular}{|c|l|c|c|}
\hline No & \multicolumn{1}{|c|}{ Variabel } & Nilai Tolerance & VIF \\
\hline 1 & $\begin{array}{l}\text { Pemahaman Good } \\
\text { Governance }\end{array}$ & 0,609 & 1,641 \\
\hline 2 & Ketidakjelasan Peran & 0,677 & 1,476 \\
\hline 3 & Komitmen Organisasi & 0,581 & 1,722 \\
\hline 4 & Kerahasiaan & 0,793 & 1,260 \\
\hline 5 & Locus of Control & 0,610 & 1,638 \\
\hline
\end{tabular}




\section{Uji Heteroskedastisitas}

Dari hasil yang sudah dilakukan mendapatkan jawaban bahwa nilai yang digunakan signifikan dan dapat dijelaskna bahwa data yang digunakan tidak mengalami gejala.

\begin{tabular}{|c|l|c|c|}
\hline No & \multicolumn{1}{|c|}{ Variabel } & $\begin{array}{c}\text { Rata-Rata } \\
\text { Skor }\end{array}$ & $\begin{array}{c}\text { Kategori } \\
\text { Penilaian }\end{array}$ \\
\hline 1 & Kinerja Auditor & 4,33 & Tinggi \\
\hline 2 & Pemahaman Good Governance & 4,37 & Tinggi \\
\hline 3 & Ketidakjelasan Peran & 4,12 & Cukup \\
\hline 4 & Komitmen Organisasi & 4,20 & Cukup \\
\hline 5 & Kerahasiaan & 4,48 & Tinggi \\
\hline 6 & Locus of Control & 3,91 & Cukup \\
\hline
\end{tabular}

\section{Uji Hipotesis}

\begin{tabular}{|c|c|c|c|c|c|c|c|c|}
\hline \multirow[b]{2}{*}{ Mode } & & \multicolumn{2}{|c|}{$\begin{array}{l}\text { Unstandardized } \\
\text { Coefficients }\end{array}$} & \multirow{2}{*}{$\begin{array}{l}\text { Standardized } \\
\text { Coefficients } \\
\text { Beta }\end{array}$} & \multirow[b]{2}{*}{$t$} & \multirow[b]{2}{*}{ Sig. } & \multicolumn{2}{|c|}{$\begin{array}{c}\text { Collinearity } \\
\text { Statistics }\end{array}$} \\
\hline & & B & Std. Error & & & & Tolerance & VIF \\
\hline \multirow[t]{6}{*}{1} & (Constant) & 42,284 & 9,102 & & 4,646 & 0,000 & & \\
\hline & $\mathrm{Xl}$ & 0,389 & 0,175 & 0,220 & 2,220 & 0,030 & 0,609 & 1,641 \\
\hline & $X 2$ & $-0,431$ & 0,179 & $-0,226$ & $-2,412$ & 0,019 & 0,677 & 1,476 \\
\hline & $X 3$ & 0,257 & 0,108 & 0,240 & 2,370 & 0,021 & 0,581 & 1,722 \\
\hline & $X_{4}$ & 0,402 & 0,179 & 0,194 & 2,239 & 0,029 & 0,793 & 1,260 \\
\hline & X5 & 0,257 & 0,121 & 0,210 & 2,127 & 0,037 & 0,610 & 1,638 \\
\hline
\end{tabular}

\section{Pembahasan}

1. Pengaruh pemahaman good governance

Dari hasil riset ini berdasarkan hasil jawaban yang sudah diperoleh dimana adanya pengaruh yang positif signifikan. Dan adanya pengaruh yang mengindikasikan bahwa adanya peningkatan pemahaman dan dapat meningkatkan kinerja.

2. Pengaruh ketidakjelasan peran

Berdasarkan hasil jawaban yang sudah diperoleh maka koefisien pada variabel ketidakjelasan yang berperan pada pengaruh negatif signifikan pada menurunnya kinerja.

3. Pengaruh komitmen organisasi
Dari hasi pengujian yang diperoleh pada variabel ini menjelaskan hasil yang positif signifikan pada meningkatnya kinerja.

4. Pengaruh kerahasiaan

Berdasarkan hasil pengujian yang sudah dilakukan terhadap jawaban yang berpengaruh positif signifikan kepada meningkatkan kinerja pada sektor.

5. Pengaruh locus of control

Dan dari hasil yang sudah dilakukan semua ini pada hasil pengujian sudah diperoleh jawaban yang adanya pengaruh yang positif signifikan positif dan meningkatkan kinerja.

\section{PENUTUP}

\section{Simpulan}

Dari uji yang sudah dilakukan sebelumnya maka mendapatkan simpulan dari semuanya berupa

1. Adanya pengaruh positif terhadap hasil jawaban dari good governance.

2. Sedangkan pada ketidakjelasan memberikan simpulan berupa hasil yang tidak berpengaruh terhadap kinerja.

3. Menurut komitmen memberikan sebuah jawaban berupa tidak berpengaruh terhadap hasil uji yang dilakukan.

4. Sedangkan pada kerahasiaan memberikan sebuah jawaban yang menjelaskan adanya pengaruh positif.

5. Dan yang terakhir menyimpulkan pada kerahasiaan yang dimana memberikan jawaban berupa hasil yang positif. 
Kepada para orang yang sedang melakukan uji ini harus sebaiknya mencoba variabel lain untuk bisa mengetahui seberapa jauh uji yang sudah dilakukan, dan memberikan rekomendasi berupa membuat maping pada penelitian sebelumnya.

\section{DAFTAR PUSTAKA}

Engelita O. Kneefel, Julie J. Sondakh, Lidia Mawikere. 2018. Pengaruh Kode Etik APIP Terhadap Kinerja Auditor Pemerintah Pada Inspektorat Provinsi Maluku Utara.

Juwita Tarigan, Anggie Charolina, Citra Evangelita, Ega Marito. 2019. Pengaruh Integritas, Obyektivitas, Kerahasiaan dan Kompetensi Terhadap Kinerja Auditor (Studi pada Auditor di Badan Pengawasan Keuangan dan Pembangunan (BPKP) Kota Medan.

Rizki Uatri Daulay.2020. Pengaruh Integritas Auditor, Independensi Auditor dan Gaya Kepemimpinan Terhadap Kinerja Auditor (Studi Kasus pada Kantor Akuntan Publik di Kota Medan). 